\title{
Article \\ Right Ventricular Volume and Function Assessment in Congenital Heart Disease Using CMR Compressed-Sensing Real-Time Cine Imaging
}

\author{
Benjamin Longère ${ }^{1, *} \mathbb{0}$, Julien Pagniez ${ }^{2}$, Augustin Coisne ${ }^{1}$, Hedi Farah ${ }^{2}$, Michaela Schmidt $^{3}$, \\ Christoph Forman ${ }^{3}(D)$, Valentina Silvestri ${ }^{2}$, Arianna Simeone ${ }^{2}$, Christos V Gkizas ${ }^{2}{ }^{\mathbb{D}}$, Justin Hennicaux ${ }^{2}$, \\ Emma Cheasty ${ }^{4}$, Solenn Toupin ${ }^{5}$, David Montaigne ${ }^{1}$ (D) and François Pontana ${ }^{1}$ (i)
}

\section{check for} updates

Citation: Longère, B.; Pagniez, J.; Coisne, A.; Farah, H.; Schmidt, M.; Forman, C.; Silvestri, V.; Simeone, A.; Gkizas, C.V; Hennicaux, J.; et al. Right Ventricular Volume and Function Assessment in Congenital Heart Disease Using CMR Compressed-Sensing Real-Time Cine Imaging. J. Clin. Med. 2021, 10, 1930. https://doi.org/10.3390/jcm10091930

Academic Editor: Mickaël Ohana

Received: 16 March 2021

Accepted: 20 April 2021

Published: 29 April 2021

Publisher's Note: MDPI stays neutra with regard to jurisdictional claims in published maps and institutional affiliations.

Copyright: (c) 2021 by the authors. Licensee MDPI, Basel, Switzerland. This article is an open access article distributed under the terms and conditions of the Creative Commons Attribution (CC BY) license (https:// creativecommons.org/licenses/by/ $4.0 /)$.
1 University of Lille, Inserm, CHU Lille, Institut Pasteur Lille, U1011—European Genomic Institute for Diabetes (EGID), F-59000 Lille, France; augustin.coisne@chru-lille.fr (A.C.); david.montaigne@chru-lille.fr (D.M.); francois.pontana@chru-lille.fr (F.P.)

2 CHU Lille, Department of Cardiovascular Radiology, F-59000 Lille, France; julien.pagniez@chru-lille.fr (J.P.); hedi.farah@chru-lille.fr (H.F.); valentina.silvestri@chru-lille.fr (V.S.); arianna.simeone@chru-lille.fr (A.S.); chgkizas@gmail.com (C.V.G.); justin.hennicaux@chru-lille.fr (J.H.)

3 MR Product Innovation and Definition, Magnetic Resonance, Siemens Healthcare GmbH, 91052 Erlangen, Germany; michaela.schmidt@siemens-healthineers.com (M.S.); christoph.forman@siemens-healthineers.com (C.F.)

4 Department of Cardiovascular Imaging, St Bartholomew's Hospital, West Smithfield, London EC1A 7BE, UK; emma.cheasty@nhs.net

5 Scientific Partnerships, Siemens Healthcare France, 93200 Saint-Denis, France; solenn.toupin@siemens-healthineers.com

* Correspondence: benjamin.longere@chru-lille.fr

Abstract: Background and objective: To evaluate the reliability of compressed-sensing (CS) real-time single-breath-hold cine imaging for quantification of right ventricular (RV) function and volumes in congenital heart disease (CHD) patients in comparison with the standard multi-breath-hold technique. Methods: Sixty-one consecutive CHD patients (mean age $=22.2 \pm 9.0$ (SD) years) were prospectively evaluated during either the initial work-up or after repair. For each patient, two series of cine images were acquired: first, the reference segmented multi-breath-hold steady-state free-precession sequence $\left(\mathrm{SSFP}_{\text {ref }}\right)$, including a short-axis stack, one four-chamber slice, and one long-axis slice; then, an additional real-time compressed-sensing single-breath-hold sequence $\left(\mathrm{CS}_{\mathrm{rt}}\right)$ providing the same slices. Two radiologists independently assessed the image quality and RV volumes for both techniques, which were compared using the Wilcoxon test and paired Student's $t$ test, Bland-Altman, and linear regression analyses. The visualization of wall-motion disorders and tricuspid-regurgitation-related signal voids were also analyzed. Results: The mean acquisition time for $\mathrm{CS}_{\mathrm{rt}}$ was $22.4 \pm 6.2$ (SD) s (95\% CI: 20.8-23.9 s) versus $442.2 \pm 89.9$ (SD) s (95\% CI: 419.2-465.2 s) for $\operatorname{SSFP}_{\text {ref }}(p<0.001)$. The image quality of $\mathrm{CS}_{\mathrm{rt}}$ was diagnostic in all examinations and was mostly rated as good $(n=49 / 61 ; 80.3 \%)$. There was a high correlation between $\mathrm{SSFP}_{\text {ref }}$ and $\mathrm{CS}_{\mathrm{rt}}$ images regarding RV ejection fraction $(49.8 \pm 7.8(\mathrm{SD}) \%$ (95\% CI: $47.8-51.8 \%)$ versus $48.7 \pm 8.6(\mathrm{SD}) \%(95 \%$ CI: 46.5-50.9\%), respectively; $r=0.94)$ and $\mathrm{RV}$ end-diastolic volume $(192.9 \pm 60.1(\mathrm{SD}) \mathrm{mL}(95 \% \mathrm{CI}$ : 177.5-208.3 mL) versus 194.9 \pm 62.1 (SD) mL (95\% CI: 179.0-210.8 mL), respectively; $r=0.98)$. In CS $_{\mathrm{rt}}$ images, tricuspid-regurgitation and wall-motion disorder visualization was good (area under receiver operating characteristic curve $(\mathrm{AUC})=0.87)$ and excellent $(\mathrm{AUC}=1)$, respectively. Conclusions: Compressed-sensing real-time cine imaging enables, in one breath hold, an accurate assessment of RV function and volumes in CHD patients in comparison with standard SSFP ref, allowing a substantial improvement in time efficiency.

Keywords: cardiac; heart; magnetic resonance; CMR; compressed sensing; congenital heart disease; GUCH; real-time imaging 


\section{Introduction}

The advent of heart surgery and percutaneous cardiac procedures has considerably improved outcomes in patients born with congenital heart disease [1]. It has led to a growing number of adult survivors with complex congenital heart diseases, with a concomitantly increasing need for imaging follow-up in this clinical context.

Right ventricular (RV) function and volume assessment is of paramount importance in many of these patients, such as in post-repair tetralogy of the Fallot population, as treatment decisions and outcomes mainly rely on RV parameters according to the European Society of Cardiology guidelines for the management of adult congenital heart disease [2]. Although echocardiography remains the first-line investigation, cardiac magnetic resonance (CMR) is a method of choice for RV morphological and functional evaluation in congenital heart disease due to its complex geometry. CMR is considered superior to echocardiography for the evaluation of RV and should be regularly used when the information is essential for patient management, i.e., for quantification of RV volume and ejection fraction, quantification of pulmonary regurgitation, evaluation of RV outflow-tract and pulmonary arteries, detection of myocardial fibrosis or scar, and tissue characterization [2].

However, one major limitation of such extensive CMR examinations is currently the acquisition time, which can be difficult to tolerate in this population, as well as the iterative breath holds, which can be difficult to maintain, leading to poor-quality examinations because of breathing artifacts. To reduce this limitation, the development of acceleration techniques in MR imaging is crucial, and compressed sensing (CS) represents a promising technique in this category. Schematically, CS is a technique that combines a strong and random $k$-space subsampling, thus enabling a very high scan speed, and it uses non-linear iterative reconstructions to make the final image look as close as possible to that if the $k$-space had been fully sampled. The use of CS for CMR cine imaging theoretically enables real-time acquisition with whole-ventricle coverage in a single breath hold, and its reliability has been successfully tested in previous studies for left ventricular (LV) or sometimes right ventricular (RV) functional assessment in healthy volunteers and in patients with various extra-congenital pathologies [3-11].

We thus aimed at evaluating the reliability of real-time cine imaging using the CS technique for quantification of RV and LV function and volumes in congenital heart disease patients in comparison with conventional multi-breath-hold segmented steady-state freeprecession cine imaging.

\section{Materials and Methods}

\subsection{Study Population}

From January to April 2019, 61 consecutive patients were prospectively included. All patients were clinically scheduled for CMR in the context of congenital heart disease for either the initial work-up or after repair. A single-ventricle anatomy was considered as an exclusion criterion. The protocol was approved by our institutional Ethics Committee, and the patients gave informed consent.

\subsection{CMR Protocol}

All CMR examinations were performed on a $1.5 \mathrm{~T}$ magnetic resonance scanner (MAGNETOM Aera, Siemens Healthcare, Erlangen, Germany). For each patient, two series of two-dimensional cine images were systematically acquired: prospectively triggered segmented multi-breath-hold steady-state free-precession sequence $\left(\mathrm{SSFP}_{\text {ref }}\right)$ was considered as the reference technique, including a conventional short-axis stack, one LV and one RV two-chamber slice, and one four-chamber slice with an $8 \mathrm{~mm}$ slice thickness and a $2 \mathrm{~mm}$ gap; an additional prospectively triggered real-time CS sequence $\left(\mathrm{CS}_{\mathrm{rt}}\right)$ in a single breath hold. $\mathrm{CS}_{\mathrm{rt}}$ cine images were acquired with the same slice number, position, and thickness as those used in the reference technique. An additional phase-contrast imaging sequence was acquired on the pulmonary trunk to assess the RV stroke volume and the severity of 
the encountered tricuspid regurgitation. The details of the imaging parameters are listed in Table 1.

Table 1. Imaging parameters of the reference steady-state free-precession cine imaging and real-time compressed-sensing cine imaging.

\begin{tabular}{|c|c|c|}
\hline Parameters & SSFP $_{\text {ref }}$ & $\mathrm{CS}_{\mathrm{rt}}$ \\
\hline Repetition time-ms & 3.16 & 2.70 \\
\hline Echo time-ms & 1.23 & 1.14 \\
\hline Flip angle-degrees & 57 & 60 \\
\hline Field of view- $\mathrm{mm}^{2}$ & $375 \times 280$ & $360 \times 270$ \\
\hline Matrix-pixels ${ }^{2}$ & $288 \times 216$ & $224 \times 168$ \\
\hline Spatial resolution- $-\mathrm{mm}^{2}$ & $1.3 \times 1.3$ & $1.6 \times 1.6$ \\
\hline Temporal resolution-ms & 41.2 & 49 \\
\hline Slice thickness/gap-mm & $8 / 2$ & $8 / 2$ \\
\hline Bandwidth-Hz/pixel & 915 & 900 \\
\hline ECG mode & Prospective triggering & Prospective triggering \\
\hline Number of measured cardiac phases per cycle & $20^{\mathrm{a}}$ & $16 \pm 4.1$ \\
\hline Reconstructed cardiac frames per cycle $-n$ & $20^{\mathrm{a}}$ & $20^{\mathrm{b}}$ \\
\hline Number of views per frame- $n$ & $13.0 \pm 3.7^{c}$ & $18^{\mathrm{a}}$ \\
\hline Number of breath holds & $13.3 \pm 2.9$ & $1^{\mathrm{a}}$ \\
\hline Cycles of iterative reconstruction $-n$ & NA & 40 \\
\hline Breath-hold duration—cardiac cycle per slice & 7 & $2^{d}$ \\
\hline Acceleration factor & 2 & 11 \\
\hline
\end{tabular}

Data are expressed as mean \pm standard deviation in the absence of any indication. ${ }^{\text {a }}$ Constant value. ${ }^{\mathrm{b}}$ Interpolation was performed to provide a constant frame rate of 20 cardiac phases per cycle for post-processing. ${ }^{c}$ The number of views per frame was set according to the shorter R-R interval in order to acquire 20 cardiac phases. ${ }^{\mathrm{d}}$ The first cardiac cycle is required for signal preparation and the second one for signal acquisition. Abbreviations: $\mathrm{SSFP}_{\text {ref }}$, reference steady-state free-precession cine; $\mathrm{CS}_{\mathrm{rt}}$, real-time compressed-sensing cine; ECG, electrocardiogram; $n$, data represented as numbers; NA, not applicable.

\subsection{Functional Evaluation}

The quantitative assessment consisted of the evaluation of RV functional parameters with both the $\mathrm{SSFP}_{\text {ref }}$ and $\mathrm{CS}_{\mathrm{rt}}$ sequences, i.e., ejection fraction (EF), end-diastolic volume (EDV), end-systolic volume (ESV), and stroke volume (SV). The same parameters were measured for the left ventricle, as well as the LV mass. For these quantitative measurements, endocardial and epicardial contours were segmented on the conventional short-axis stacks of cine images using a dedicated analysis software (Cardiac MR analysis workflow, Syngo.via VB30A, Siemens Healthcare, Erlangen, Germany). According to our CMR practice, RV trabeculations were included in the RV volume. Four-chamber and long-axis slices were used as reference images to trace the atrio-ventricular valve planes to ensure an optimal delineation of the heart base for an accurate volume calculation.

\subsection{Image Quality Assessment}

The overall subjective image quality of the $\mathrm{SSFP}_{\text {ref }}$ and $\mathrm{CS}_{\text {rt }}$ cine images was rated on the basis of a four-point Likert scale as follows: $4=$ excellent, $3=$ good, $2=$ fair image quality, and 1 = non-diagnostic examination.

In addition, the objective RV image quality was assessed using previously published criteria, which are mostly based on artifact rating, and they were adapted to the RV [12]. Schematically, 1 point was given if an artifact (fold-over, respiratory ghost, cardiac ghost, image blurring/mistriggering, metallic, or shimming) hampered the visualization of the $\mathrm{RV}$ border at the end-systole and/or end-diastole; if such an artifact involved 2 or $\geq 3$ slices, 2 or 3 points were given, respectively.

The depictions of the regional RV wall-motion abnormalities (i.e., hypokinetic, akinetic, or dyskinetic wall) were also rated at 4 anatomical levels (base, mid-cavity, apex, and RV outflow tract), and the depictions of tricuspid-regurgitation-related flow artifacts were assessed on the four-chamber slice. 


\subsection{Conditions of Image Analysis}

The acquired $\mathrm{SSFP}_{\text {ref }}$ and $\mathrm{CS}_{\mathrm{rt}}$ cine images were independently analyzed offline by a $\mathrm{CMR}$ radiologist $(\mathrm{HF})$ with 3 years of experience. After anonymization, the images from both sequences were randomized and mixed. The two types of cine sequences from one patient were not read in the same session. A radiologist (JP) with 10 years of experience performed the functional RV assessment on a 20-patient sample for the determination of interobserver agreement with the new CS cine technique [13].

\subsection{Statistical Analysis}

Categorical data are represented as numbers (percentages). Continuous variables are represented as mean \pm standard deviation (SD) (95\% confidence interval (CI)) in the case of normal distribution and median (range: minimum-maximum) in other cases. SSFP ref $_{\text {f }}$ and $\mathrm{CS}_{\mathrm{rt}}$ were compared using paired Student's $t$ test, Bland-Altman, and linear regression analyses. The interobserver agreement of $\mathrm{CS}_{\mathrm{rt}}$ was determined by calculating the intra-class correlation coefficient. An analysis of variance was performed to compare the RV stroke volumes assessed with both cine sequences with the forward pulmonary volume assessed with PCI. Differences in quality scores between SSFP $_{\text {ref }}$ and CS $_{\text {rt }}$ were assessed using the Wilcoxon test. Values of $p<0.05$ were considered statistically significant. For the depictions of valvular regurgitations and wall-motion disorders, a receiver operating characteristic (ROC) curve was used. The statistical analysis was performed with dedicated software (MedCalc 18.11, MedCalc Software bvba, Ostend, Belgium).

\section{Results}

\subsection{Population Description}

The 61 patients ( 29 men, 32 women; mean age: $22.2 \pm 9.0$ (SD) years; $95 \%$ CI: 19.9-24.5 years) underwent CMR for: tetralogy of Fallot $(n=33 / 61 ; 54.1 \%)$, pulmonary atresia with a ventricular septal defect $(n=7 / 61 ; 11.5 \%)$, cardiac shunt $(n=7 / 61 ; 11.5 \%)$, transposition of great arteries $(n=3 / 61 ; 4.9 \%)$, aortic coarctation $(n=2 / 61 ; 3.3 \%)$, congenital pulmonary stenosis $(n=2 / 61 ; 3.3 \%)$, cor triatriatum sinister $(n=2 / 61 ; 3.3 \%)$, congenitally corrected transposition of the great arteries $(n=2 / 61 ; 3.3 \%)$, pulmonary atresia with intact ventricular septum after biventricular repair $(n=2 / 61 ; 3.3 \%)$, and congenital aortic stenosis $(n=1 / 61$; $1.6 \%)$. Table 2 summarizes further details of the characteristics of the study population.

Table 2. Study population characteristics.

\begin{tabular}{cccc}
\hline & Mean \pm SD (95\% CI) & Minimum Value & Maximum Value \\
\hline Age-years & $22.0 \pm 9.0(19.9-24.5)$ & 7 & 53 \\
Weight-kg & $59.1 \pm 16.8(54.8-63.4)$ & 24 & 100 \\
Height-cm & $163.4 \pm 15.0(159.5-167.2)$ & 121 & 190 \\
Body surface area-m ${ }^{2}$ & $1.6 \pm 0.3(1.6-1.7)$ & 0.9 & 2.3 \\
Heart rate-beats per minute & $74.6 \pm 14.2(71.0-78.2)$ & 44 & 112 \\
\hline
\end{tabular}

Abbreviations: SD, standard deviation; 95\% CI, 95\% confidence interval.

\subsection{Cine Acquisitions}

The mean duration for single-breath-hold $\mathrm{CS}_{\mathrm{rt}}$ acquisition was $22.4 \pm 6.2$ (SD) s (95\% CI: 20.8-23.9 s) versus $442.2 \pm 89.9$ (SD) s (95\% CI: 419.2-465.2 s) for $\operatorname{SSFP}_{\text {ref }}(p<0.001$ ). The mean acceleration factor provided by $\mathrm{CS}_{\mathrm{rt}}$ was $20.8 \pm 5.6$ (95\% CI: 19.3-22.2) as compared with $\mathrm{SSFP}_{\text {ref }}$. A mean number of $13.3 \pm 2.9$ slices (95\% CI: $12.5-14.1$ slices) was acquired with each sequence.

\subsection{Quantitative Evaluation}

Detailed results regarding the SSFP ref and $\mathrm{CS}_{\mathrm{rt}}$ segmentations for the RV and LV functional parameters are presented in Table 3 . There was no statistically significant difference between mean SSFP ref $_{\text {and }}$ CS $_{\text {rt }}$ for RVEDV (192.9 \pm 60.1 (SD) mL (95\% CI: 177.5-208.3 mL) 
versus $194.9 \pm 62.1(\mathrm{SD}) \mathrm{mL}$ (95\% CI: 179.0-210.8 mL), respectively; $p=0.169)$. The RVEF was slightly underestimated in the $\mathrm{CS}_{\mathrm{rt}}$ images (CS $\mathrm{CS}_{\mathrm{rt}}: 48.7 \pm 8.6(\mathrm{SD}) \%$ (95\% CI: 46.5-50.9\%); SSFP $_{\text {ref }}: 49.8 \pm 7.8$ (SD) \% (95\% CI: $\left.\left.47.8-51.8 \%\right) ; p=0.006\right)$ as a result of a statistically significant but not clinically relevant underestimation of the RVESV in $\mathrm{CS}_{\mathrm{rt}}$. The analysis of variance did not demonstrate any significant differences with respect to the RV stroke volume, regardless of the measurement method (SSFP ref: $93.6 \pm 25.7$ (SD) mL (95\% CI: 87.0-100.2 mL); CS ${ }_{\mathrm{rt}}$ : $92.3 \pm 26.0$ (SD) mL (95\% CI: 85.7-99.0 mL); PCI: $88.6 \pm 27.1$ (SD) $\mathrm{mL}(95 \% \mathrm{CI}: 91.6-95.5 \mathrm{~mL}) ; p=0.605)$. No statistically significant differences were visible between SSFP $_{\text {ref }}$ and CS $_{\text {rt }}$ for LVEF and LVEDV. The LV mass was slightly overestimated in $\mathrm{CS}_{\mathrm{rt}}$. The linear regression yielded good agreement between both acquisition techniques for all RV functional parameters (Figure 1), and the $r$ values were excellent for all parameters. On the other hand, graphical analysis of the Bland-Altman plot demonstrated up to five (tetralogy of Fallot, $n=5 / 5 ; 100 \%$ ) paired measurements out of the limits of agreement (LOA) depending on the RV parameter considered (LOA in RVEF bias: -13.7 to $+9.3 \%$ ).

Table 3. Functional parameters segmented on both the reference steady-state free-precession and real-time compressedsensing cine.

\begin{tabular}{|c|c|c|c|c|c|c|}
\hline & \multirow{2}{*}{$\begin{array}{c}\mathrm{SSFP}_{\text {ref }} \text { Sequence } \\
(\text { mean } \pm \mathrm{SD}(95 \% \mathrm{CI}))\end{array}$} & \multirow{2}{*}{$\begin{array}{c}\mathrm{CS}_{\mathrm{rt}} \text { Sequence } \\
(\mathrm{mean} \pm \mathrm{SD}(95 \% \mathrm{CI}))\end{array}$} & \multirow{2}{*}{$\begin{array}{l}\text { Mean Difference } \\
\pm \text { SD (95\% CI) }\end{array}$} & \multirow{2}{*}{ Paired $t$ Test $p$} & \multicolumn{2}{|c|}{ ICC } \\
\hline & & & & & Inter & Intra \\
\hline RVEF-\% & $\begin{array}{c}49.8 \pm 7.8 \\
(47.8-51.8)\end{array}$ & $\begin{array}{l}48.7 \pm 8.6 \\
(46.5-50.9)\end{array}$ & $\begin{array}{c}-1.07 \pm 2.90 \\
(-1.81 \text { to }-0.32)\end{array}$ & 0.006 & 0.95 & 0.94 \\
\hline $\mathrm{RVEDV}-\mathrm{mL}$ & $\begin{array}{r}192.9 \pm 60.1 \\
(177.5-208.3)\end{array}$ & $\begin{array}{c}194.9 \pm 62.1 \\
(179.0-210.8)\end{array}$ & $\begin{array}{c}2.00 \pm 11.21 \\
(-0.87 \text { to } 4.87)\end{array}$ & 0.169 & 0.91 & 0.97 \\
\hline RVESV-mL & $\begin{array}{l}98.9 \pm 41.0 \\
(88.4-109.4)\end{array}$ & $\begin{array}{l}102.4 \pm 44.0 \\
(91.1-113.7)\end{array}$ & $\begin{array}{c}3.51 \pm 11.05 \\
(0.68-6.34)\end{array}$ & 0.016 & 0.97 & 0.98 \\
\hline RVSV-mL & $\begin{array}{l}93.6 \pm 25.7 \\
(87.0-100.2)\end{array}$ & $\begin{array}{l}92.3 \pm 26.0 \\
(85.7-99.0)\end{array}$ & $\begin{array}{c}-1.28 \pm 2.96 \\
(-2.04 \text { to }-0.52)\end{array}$ & 0.001 & 0.99 & 0.93 \\
\hline LVEF_\% $\%$ & $\begin{array}{l}57.4 \pm 7.5 \\
(55.4-59.3)\end{array}$ & $\begin{array}{l}57.8 \pm 7.9 \\
(55.7-59.8)\end{array}$ & $\begin{array}{c}0.38 \pm 4.22 \\
(-0.70 \text { to } 1.46)\end{array}$ & 0.488 & 0.98 & 0.98 \\
\hline LVEDV-mL & $\begin{array}{r}130.0 \pm 40.1 \\
(119.8-140.3)\end{array}$ & $\begin{array}{c}128.7 \pm 43.6 \\
(117.5-139.8)\end{array}$ & $\begin{array}{l}-1.39 \pm 10.68 \\
(-4.13 \text { to } 1.34)\end{array}$ & 0.312 & 0.98 & 0.97 \\
\hline LVESV—mL & $\begin{array}{l}56.3 \pm 23.5 \\
(50.3-62.3)\end{array}$ & $\begin{array}{l}55.5 \pm 27.1 \\
(48.5-62.4)\end{array}$ & $\begin{array}{l}-0.84 \pm 10.24 \\
(-3.46 \text { to } 1.79)\end{array}$ & 0.526 & 0.97 & 0.98 \\
\hline LVSV-mL & $\begin{array}{l}73.6 \pm 21.9 \\
(68.0-79.2)\end{array}$ & $\begin{array}{l}73.4 \pm 22.1 \\
(67.7-79.0)\end{array}$ & $\begin{array}{l}-0.23 \pm 3.14 \\
(-1.03 \text { to } 0.58)\end{array}$ & 0.571 & 0.99 & 0.99 \\
\hline $\mathrm{LVM}-\mathrm{g}$ & $\begin{array}{r}95.7 \pm 33.9 \\
(87.0-104.4)\end{array}$ & $\begin{array}{l}102.9 \pm 38.5 \\
(93.0-112.8)\end{array}$ & $\begin{array}{c}7.18 \pm 15.12 \\
(3.31 \text { to } 11.05)\end{array}$ & 0.0005 & 0.96 & 0.97 \\
\hline
\end{tabular}

ICC was used to evaluate the interobserver agreement for the RV segmentation. The significance of Student's $t$ test is defined by $p<0.05$. Abbreviations: $\mathrm{SSFP}_{\text {ref }}$, reference steady-state free-precession cine; $\mathrm{CS}_{\mathrm{rt}}$, real-time compressed-sensing cine; $\mathrm{SD}$, standard deviation; $95 \% \mathrm{CI}$, $95 \%$ confidence interval; RV, right ventricular; LV, left ventricular; EDV, end-diastolic volume; ESV, end-systolic volume; SV, stroke volume; LVM, left ventricular mass; ICC, intraclass correlation coefficient; Inter, interobserver; Intra, intraobserver.

\subsection{Qualitative Evaluation}

Figure 2; Figure 3; Video S1; Video S2 (Supplementary Materials) provide representative examples of the image quality achieved with $\mathrm{CS}_{\mathrm{rt}}$ images in various clinical situations. The image quality of $\mathrm{CS}_{\mathrm{rt}}$ was diagnostic in all examinations (Table 4). There was a significantly lower overall image quality score for $\mathrm{CS}_{\mathrm{rt}}$ images $(p=0.0001)$ because most of the examinations were rated as excellent with $S_{S F P}$ ref and good with $C_{\text {rt }}$. However, qualitative artifact presence was statistically lower in the $\mathrm{CS}_{\mathrm{rt}}$ images than in $\operatorname{SSFP}_{\text {ref }}(p=0.0016)$. Considering SSFP $_{\text {ref }}$ as the gold standard, there were no diagnostic losses for regional RV wall-motion abnormalities in $\mathrm{CS}_{\mathrm{rt}}$ images, demonstrating a $100 \%$ sensitivity and specificity (normokinetic: $n=157 / 244(64.3 \%)$; hypokinetic: $n=39 / 244(16.0 \%)$; akinetic: $n=1 / 244$ (0.4\%); dyskinetic: $n=47 / 244(19.3 \%))$. The tricuspid-regurgitation-flow void depictions in $\mathrm{CS}_{\mathrm{rt}}$ images had a sensitivity and specificity of $74.2 \%$ and $100 \%$, respectively (predictive positive value $=100 \%$; predictive negative value $=78.9 \%$; area under $\mathrm{ROC}=0.87$ ). Using 
$\mathrm{SSFP}_{\text {ref }}, 23 / 61$ (37.7\%) tricuspid regurgitations were depicted (mild: $20 / 23$ (87.0\%); moderate: $3 / 23(13.0 \%))$. Of the $8 / 61(13.1 \%)$ tricuspid regurgitations that were not depicted with the $\mathrm{CS}_{\mathrm{rt}}$ cine, all were quantified as mild with the reference technique (the difference between RVSV and anterograde pulmonary volume was measured with the phase-contrast sequence) [14].

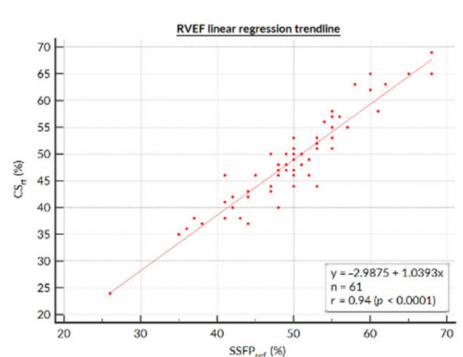

(a)

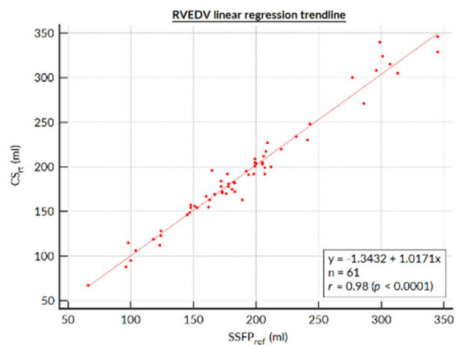

(c)

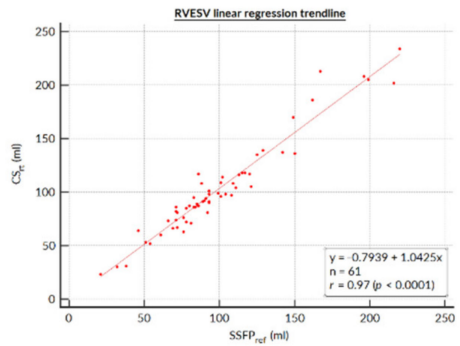

(e)

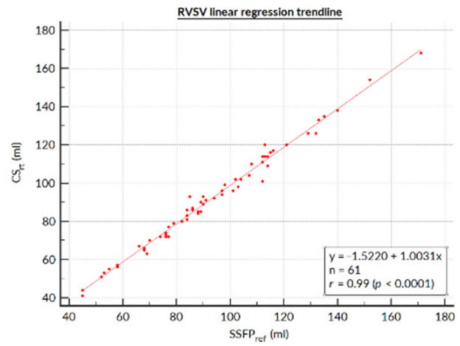

(g)

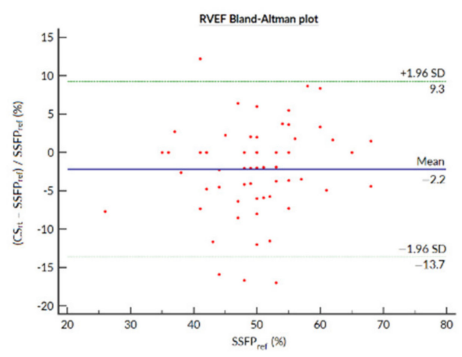

(b)

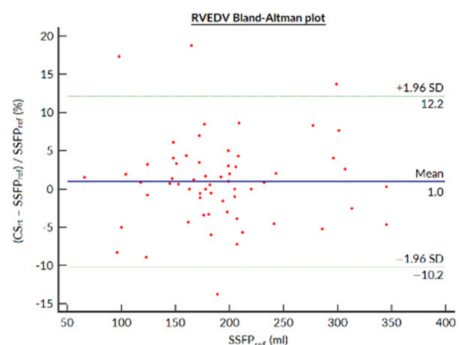

(d)

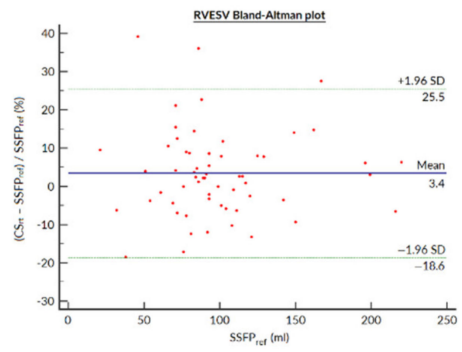

(f)

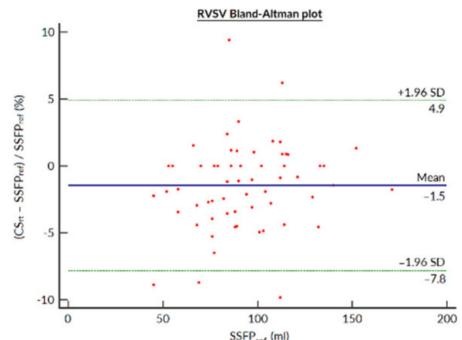

(h)

Figure 1. Bland-Altman plots and linear regression trendlines for quantification of the right ventricular functional parameters. Left column: Linear regression trend lines for (a) RVEF, (c) RVEDV, (e) RVESV, and (g) RVSV, representing the correlation between parameters measured on the SSFP ref and $\mathrm{CS}_{\text {rg }}$ sequences. Right column: Bland-Altman plots for the (b) RVEF, (d) RVEDV, (f) RVESV, and (h) RVSV. Solid blue lines are the mean differences and dashed green lines are the $95 \%$ limits of agreement. Abbreviations: $\mathrm{SSFP}_{\text {ref }}$, reference steady-state free-precession cine; $\mathrm{CS}_{\mathrm{rt}}$, real-time compressed-sensing cine; SD, standard deviation; RVEF, right ventricular ejection fraction; RVEDV, right ventricular end-diastolic volume; RVESV, right ventricular end-systolic volume; RVSV, right ventricular stroke volume. 


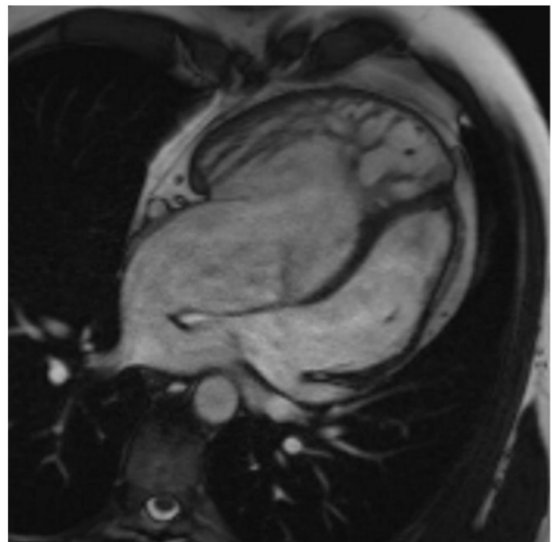

(a)

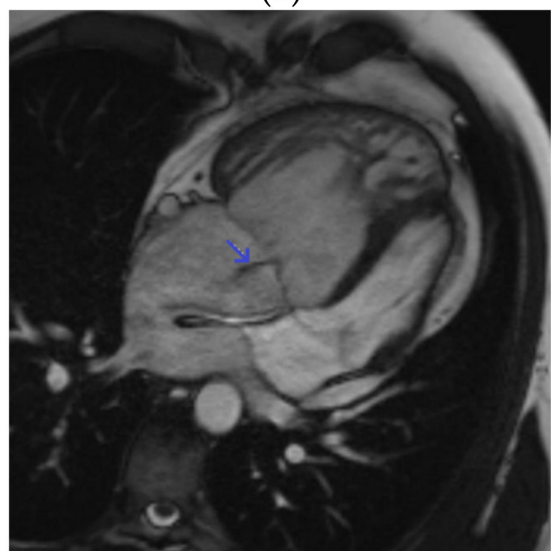

(c)

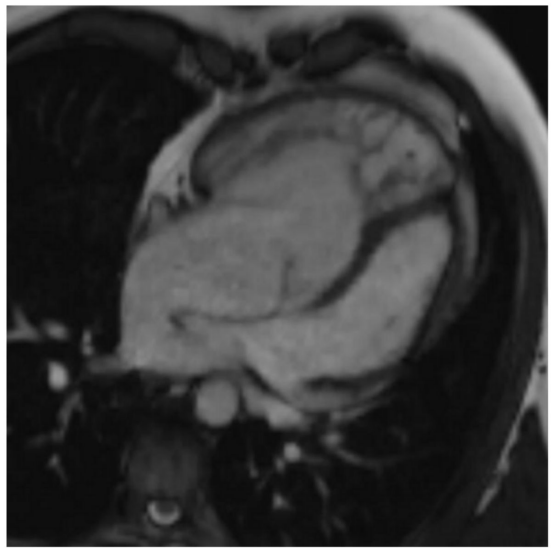

(b)

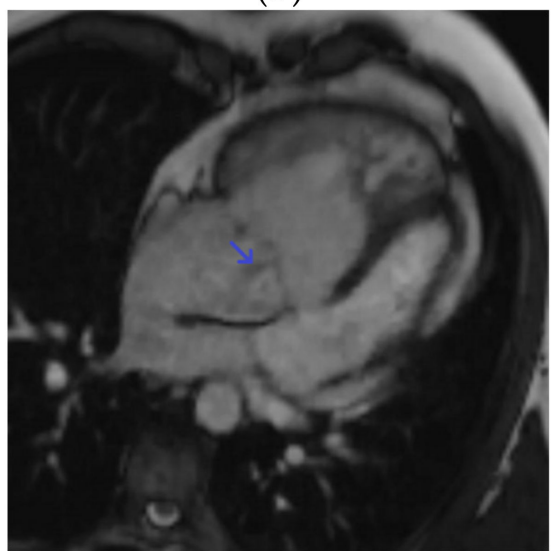

(d)

Figure 2. Four-chamber cine slice acquired with both sequences in a 31-year-old male patient referred for transposition of great arteries after a Senning repair follow-up. SSFP ref view in the diastole (a) and systole (c); overall image quality score $=4 / 4 ; \mathrm{RVEF}=42 \%$; $\mathrm{EDV}=345 \mathrm{~mL}$. The same slices acquired with $\mathrm{CS}_{\mathrm{rt}}$ in the diastole (b) and systole (d); overall image quality score $=3 / 4 ; \mathrm{RVEF}=40 \%$; $\mathrm{EDV}=346 \mathrm{~mL}$. The tricuspid regurgitation flow artifact remains conspicuous with both sequences (blue arrow). Abbreviations: $\mathrm{SSFP}_{\text {ref, }}$, reference steady-state free-precession cine; $\mathrm{CS}_{\mathrm{rt}}$, real-time compressed-sensing cine; RVEF, right ventricular ejection fraction; EDV, end-diastolic volume.

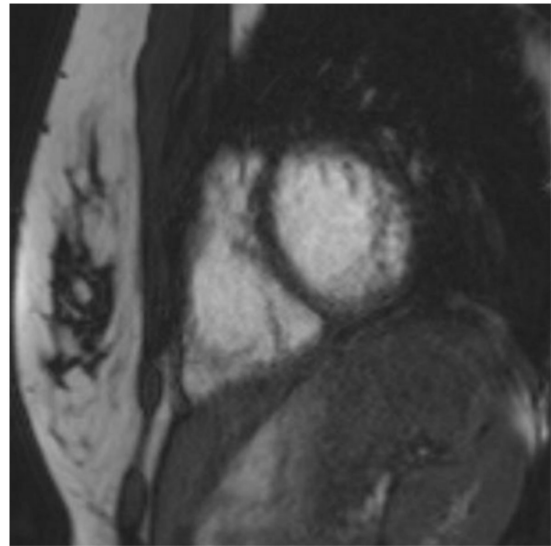

(a)

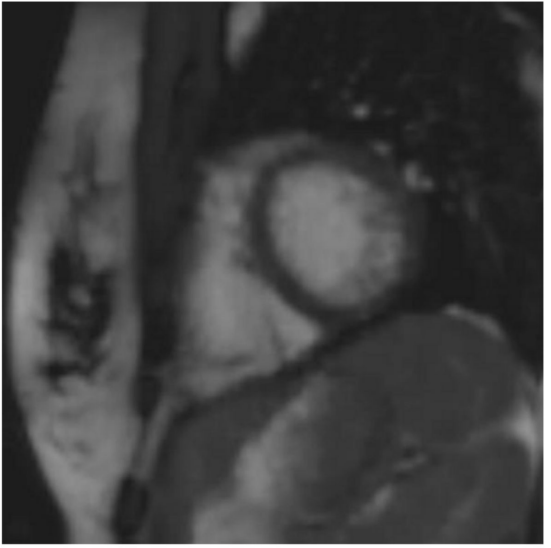

(b)

Figure 3. Cont. 


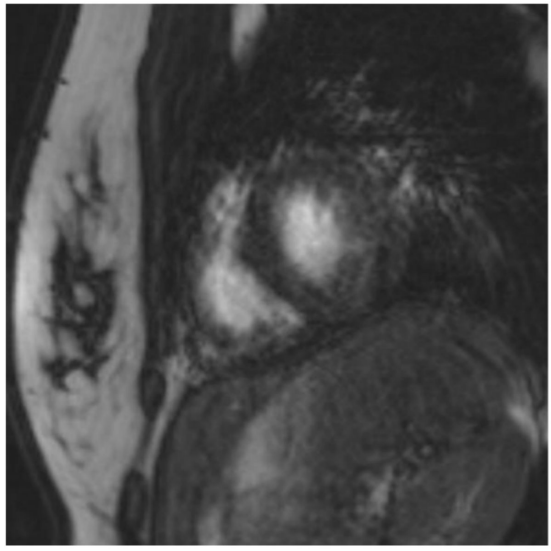

(c)

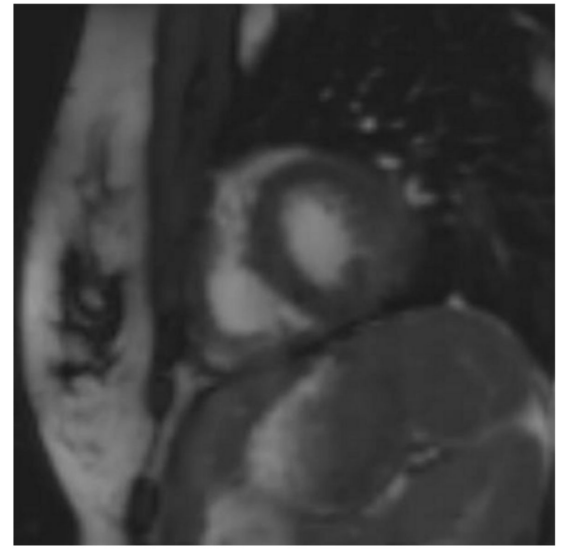

(d)

Figure 3. Short-axis cine slice acquired with both sequences in a 26-year-old female patient referred for a tetralogy of Fallot post-repair follow-up, demonstrating an irregular heart rate. Mean heart rate $=78 \pm 14(\mathrm{SD}) \mathrm{bpm}$ (range: 51 to $107 \mathrm{bpm}$ ). SSFP ref view in the diastole (a) and systole (c); overall image quality score $=2 / 4 ; \mathrm{RVEF}=51 \%$; EDV $=148 \mathrm{~mL}$. The same slices were acquired with $\mathrm{CS}_{\mathrm{rt}}$ in the diastole $(\mathbf{b})$ and systole $(\mathbf{d})$; overall image quality score $=3 / 4 ; \mathrm{RVEF}=48 \%$; EDV $=154 \mathrm{~mL}$. The fair image quality is due to the mis-triggering of artifacts in $\mathrm{SSFP}_{\text {ref }}$, while CS $_{\mathrm{rt}}$ provided both accurate segmentation and good image quality. Abbreviations: bpm, beats per minute; SD, standard deviation; $\mathrm{SSFP}_{\text {ref }}$, reference steady-state free-precession cine; $\mathrm{CS}_{\mathrm{rt}}$, real-time compressed-sensing cine; RVEF, right ventricular ejection fraction; EDV, end-diastolic volume.

Table 4. Qualitative assessment of the reference steady-state free-precession cine and real-time compressed-sensing cine.

\begin{tabular}{|c|c|c|c|c|c|c|c|}
\hline & \multicolumn{4}{|c|}{ Overall image quality score } & \multicolumn{3}{|c|}{ CMR RV artifact score } \\
\hline & $\begin{array}{c}\text { Score } 1 \\
\text { Non-diagnostic }\end{array}$ & Score 2 Fair & Score 3 Good & Score 4 Excellent & Score $0-3$ & Score $4-6$ & Score $7-10$ \\
\hline $\mathrm{SSFP}_{\text {ref }}-n(\%)$ & $1 / 61(1.6 \%)$ & $10 / 61(16.4 \%)$ & $22 / 61(36.1 \%)$ & $28 / 61(45.9 \%)$ & $47 / 61(77.1 \%)$ & $11 / 61(18.0 \%)$ & $3 / 61(4.9 \%)$ \\
\hline $\mathrm{CS}_{\mathrm{rt}}-n(\%)$ & $0 / 61(0.0 \%)$ & $12 / 61(19.7 \%)$ & $49 / 61(80.3 \%)$ & $0 / 61(0.0 \%)$ & $55 / 61(90.2 \%)$ & $6 / 61(9.8 \%)$ & $0 / 61(0.0 \%)$ \\
\hline$p$-value & \multicolumn{4}{|c|}{0.0001} & \multicolumn{3}{|c|}{0.0016} \\
\hline \multicolumn{8}{|c|}{$\begin{array}{l}\text { The significance of the Wilcoxon test is defined by } p<0.05 \text {. Abbreviations: } \mathrm{SSFP}_{\text {ref, }} \text {, reference steady-state free-precession cine; } \mathrm{CS}_{\mathrm{rt}} \text {, real-time compressed-sensing cine } \\
\qquad(\%) \text {, data represented as numbers (percentages); CMR, cardiac magnetic resonance; } \mathrm{RV} \text {, right ventricle. }\end{array}$} \\
\hline \multicolumn{8}{|c|}{ b. Diagnostic performance crosstabulation for tricuspid-regurgitation-flow-related artifact depiction. } \\
\hline & \multicolumn{3}{|c|}{ SSFP $_{\text {ref }}:$ TR+ } & SSFP $_{\text {ref }}:$ TR - & \multicolumn{3}{|c|}{ Total } \\
\hline $\mathrm{CS}_{\mathrm{rt}}: \mathrm{TR}+$ & \multicolumn{3}{|c|}{$23 / 61(37.7 \%)$} & $0(0.0 \%)$ & \multicolumn{3}{|c|}{$23 / 61(37.7 \%)$} \\
\hline $\mathrm{CS}_{\mathrm{rt}}: \mathrm{TR}-$ & \multicolumn{3}{|c|}{$8 / 61(13.1 \%)$} & $30(49.2 \%)$ & \multicolumn{3}{|c|}{$38 / 61(62.3 \%)$} \\
\hline Total & \multicolumn{3}{|c|}{$31 / 61(50.8 \%)$} & $30 / 61(49.2 \%)$ & \multicolumn{3}{|c|}{$61 / 61(100.0 \%)$} \\
\hline \multicolumn{8}{|c|}{$\begin{array}{l}\text { Considering } \mathrm{SSFP}_{\text {ref }} \text { as the gold standard, } \mathrm{CS}_{\mathrm{rt}} \text { demonstrated the following diagnostic performances for the depiction of tricuspid-regurgitation-flow-related artifacts: } \\
\text { sensitivity }=74.2 \% \text {; specificity }=100 \% \text {; positive predictive value }=100 \% \text {; negative predictive value }=78.9 \% \text {; area under ROC }=0.87 \text {. Abbreviations: } \mathrm{SSFP} \text { ref, reference } \\
\text { steady-state free-precession cine; } \mathrm{CS}_{\mathrm{rt}} \text {, real-time compressed-sensing cine; TR+, conspicuous tricuspid-regurgitation-flow-related artifact; TR-, no } \\
\text { tricuspid-regurgitation-flow-related artifact depicted; ROC, receiver operating characteristic. }\end{array}$} \\
\hline
\end{tabular}

\section{Discussion}

Our prospective monocentric study based on a cohort of 61 pediatric and grown-up CHD patients, including 33 tetralogies of Fallot, demonstrated that the quantification of RV function and volumes yields similar results for $\mathrm{CS}_{\mathrm{rt}}$ and for the standard SSFP ref cine techniques, while the former allows a drastically shorter acquisition time. The agreement between $\mathrm{CS}_{\mathrm{rt}}$ and $\mathrm{SSFP}_{\text {ref }}$ regarding the RV volume assessment is in line with the findings of previous studies performed on smaller cohorts of healthy volunteers and non-CHD patients $[5,10]$. The $t$ test comparisons performed in our study demonstrated a statistically significant trend towards a 1.07\% RVEF underestimation (relative mean difference $=-2.14 \%$ ), a $3.51 \mathrm{~mL}$ RVESV overestimation (relative mean difference $=3.54 \%$ ), and a $1.28 \mathrm{~mL} \mathrm{RVSV}$ underestimation (relative mean difference $=-1.36 \%$ ) with $\mathrm{CS}_{\mathrm{rt}}$. The segmented steady-state free precession cine is currently considered the gold-standard technique for the measure- 
ment of ventricular volumes, including in CHD patients [2,15-17]. However, these trends must be balanced with the clinically relevant LOA demonstrated in the Bland-Altman plots, mainly regarding the relative bias of RVEF $(-13.7 ;+9.3 \%)$, which was also the case in other studies evaluating CS cine for RV assessment in non-CHD populations, where the LOA was reported to be from -10.5 to $+11.6 \%[5,10,18,19]$. A more recent study also found a similar performance of a novel real-time steady-state free precession spiral sequence reconstructed using CS in a pediatric-only CHD population, but did not evaluate the regional wall-motion abnormalities or the depiction of tricuspid-regurgitation-related flow artifacts [19]. It must also be highlighted that both intra- and interobserver agreement was excellent for all $\mathrm{CS}_{\mathrm{rt}}$-evaluated RV functional parameters. Additionally, our findings demonstrate a strong agreement between both SSFP $_{\text {ref }}$ and CS $_{\text {rt }}$ for functional LV parameters, despite the slight LV mass overestimation with $\mathrm{CS}_{\mathrm{rt}}$, as previously reported [5].

The best image plane required for post-processing of RV volumes has long been debated, especially in the clinical context of CHD. However, it has been shown that despite a trend favoring the axial plane rather than the short axis in terms of reproducibility, there were no clinically significant differences between these two contouring methods [20]. Thus, we drew RV endocardial contours on short-axis stacks, as this is widely performed and is easier to set up in routine practice, but care was taken to trace the tricuspid valve on reference four-chamber and RV long-axis slices to delimit the right ventricular basis as precisely as possible. Despite controversies about segmentation methods, we included trabeculations in RV volumes according to our CMR center's habits [21]. The justification for this choice lies in the need for consistency in our practice in order to preserve reproducibility in patient follow-ups [22,23]. Nevertheless, we acknowledge that excluding trabeculations from the blood volume could be more accurate [24]. This could explain the lower dispersion of the differences in parameters measured with SSFP $_{\text {ref }}$ and CS $_{\text {rt }}$ on Bland-Altman plots when the RVEF or RVESV increase (Figure 1b,h).

The $\mathrm{CS}_{\mathrm{rt}}$ images were diagnostic in all examinations, but the overall image quality score was, as expected, significantly lower with this technique. This can be explained by the lower edge definition provided by CS, which resulted in a slightly blurry aspect of the images. This should be addressed by using a two-shot variant of the evaluated compressed-sensing cine, which would provide an improved edge sharpness and would preserve the important scan time reduction [25]. Nevertheless, this two-shot variant has not yet been evaluated for the right ventricular functional parameters and should be the subject of further study. However, a lower RV artifact score was found with $\mathrm{CS}_{\mathrm{rt}}$ due to the reduction of artifacts-which were mostly related to mis-triggering-achieved with this real-time acquisition technique. In addition, the performance of $\mathrm{CS}_{\mathrm{rt}}$ for RV wall-motion disorder depiction was very high, as there was no diagnostic loss in comparison with the reference images, and only mild tricuspid regurgitations were not depicted with $\mathrm{CS}_{\mathrm{rt}}$ cine (Figure 2; Video S1 (Supplementary Materials)). These findings are in line with a recently published study evaluating the same real-time CS cine sequences for both LV and RV assessment in a non-selected adult cohort [18].

The $\mathrm{CS}_{\mathrm{rt}}$ sequence consisted of a single-breath-hold cine acquisition; however, some patients could not fully achieve the required apnea due to their clinical condition. They were not excluded from the study, as our aim was to be as representative as possible of our CHD population that we encounter in daily practice. Despite these free-breathing ends of acquisition, no major artifacts (CMR RV quality score $>7 / 10$ ) were noticed in the $\mathrm{CS}_{\mathrm{rt}}$ images, which all had diagnostic quality. These findings strongly suggest the possibility of the free-breathing acquisition of $\mathrm{CS}_{\mathrm{rt}}$ cine, which is particularly relevant for pediatric or end-stage CHD patients. Although the aim of this study was not to evaluate free-breathing imaging protocol, free-breathing $\mathrm{CS}_{\mathrm{rt}}$ has been demonstrated to be a reliable alternative that allows faster acquisition than sequences based on registration of multiple acquisitions and motion-correction algorithms $[9,26]$. The acceleration provided by $\mathrm{CS}_{\mathrm{rt}}$ may allow one to either (a) shorten breath-holding duration by splitting the stacks of cine slices to reduce the number of cine loops acquired per breath hold, especially for patients with shortness 
of breath, or (b) to shorten the overall examination duration, as suggested in the present study (average: $22 \mathrm{~s}\left(\mathrm{CS}_{\mathrm{rt}}\right)$ versus $7 \mathrm{~min}$ and $22 \mathrm{~s}\left(\mathrm{SSFP}_{\text {ref }}\right)$ for 13 cine slices) to improve the clinical workflow and tolerance in children or to spare examination time in order to acquire additional sequences. Indeed, a comprehensive study of hemodynamic patterns is a key point in the initial work-up of CHD or in repair follow-up. Four-dimensional (4D) flow is a promising but time-consuming technique that may take advantage of the thusly spared time $[27,28]$. Depending on the sequence design, this technique may provide both qualitative and quantitative assessments of flow patterns and ventricular volumes [29]. As extended examination durations are an obstacle for the routine use of $4 \mathrm{D}$ flow, compressedsensing $4 \mathrm{D}$ flow prototypes are also being developed [30-32].

Another interesting point is the decrease in the mis-triggering artifacts observed with $\mathrm{CS}_{\text {rt }}$ (Figure 3; Video S2 (Supplementary Materials)). Even though it was not the purpose of our study and would require further dedicated studies, this finding suggests that $\mathrm{CS}_{\mathrm{rt}}$ might have an important part to play for functional or WMD evaluations in patients with irregular heart rates [33].

\section{Limitations}

The minimum age in our population was 7 years, and further studies would be needed for validation in younger children. We also have to report that despite the drastic decrease in acquisition time, the data reconstruction process was more time consuming than with $\mathrm{SSFP}_{\text {ref }}$, as 2 min were necessary in order to visualize the whole cine stack in spite of a graphics processing unit upgrade.

Regarding the blurry aspect of images that we observed with CS, it must be said that the $\mathrm{CS}_{\mathrm{rt}}$ sequence was designed in order to reduce the acquisition time as much as possible. In a different way, some authors have successfully tested CS cine to improve the spatial or temporal resolution with quite similar or even moderately shorter acquisition times than those for reference SSFP ref, or even to achieve three-dimensional cine acquisitions [34-36]. Our scan time was, however, strongly reduced, as low as $22.4 \pm 6.2$ (SD) s versus about 6 to $10 \mathrm{~min}$ for segmented multi-breath-hold SSFP $_{\text {ref }}$, which can be very useful for patient comfort and workflow.

Although it is in line with the current literature, the bias observed between the two sequences in RVEF measurement $(\sim 10 \%)$ is clinically relevant and must be taken into consideration in CHD follow-up [37,38]. The reason for such a bias may lie in the edge sharpness impairment induced by $\mathrm{CS}_{\mathrm{rt}}$ as compared to $\mathrm{SSFP}_{\text {ref }}$ [18]. Indeed, the partial Fourier and the interpolation performed to provide a constant cardiac frame rate for postprocessing induced a smoother and blurrier endocardial delineation than conventional cine. This limitation should be responsible for the increased bias in segmentation between the two techniques and may be solved by a multi-shot approach to CS acceleration [25].

\section{Conclusions}

Compressed-sensing real-time cine imaging enables the assessment RV function and volumes in patients with CHD while providing a significant reduction in examination duration and allowing an improvement in time efficiency and patient care.

Supplementary Materials: The following are available online at https:/ / www.mdpi.com/article / 10.3390/jcm10091930/s1, Video S1: Four-chamber cine slice in a 31-year-old male patient referred for transposition of great arteries after a Senning repair (same patient as Figure 2); Video S2: Fourchamber cine slice in a 27-year-old female patient referred for tetralogy of Fallot follow-up.

Author Contributions: B.L.: data collection, interpretation and analysis, drafting of the manuscript, critical revision for important intellectual content; J.P.: study conception and design, data collection, interpretation and analysis, drafting of the manuscript, critical revision for important intellectual content; A.C.: study conception, critical revision for important intellectual content; H.F.: data collection, interpretation and analysis, drafting of the manuscript; M.S.: study conception and design, critical revision for important intellectual content; C.F.: study conception and design, critical revision for important intellectual content; V.S.: data collection and interpretation, critical revision for important 
intellectual content; A.S.: data collection and interpretation, critical revision for important intellectual content; C.V.G.: data collection and interpretation, critical revision for important intellectual content; J.H.: data collection and interpretation, critical revision for important intellectual content; E.C.: study conception, critical revision for important intellectual content; S.T.: study conception and design, critical revision for important intellectual content; D.M.: study conception, critical revision for important intellectual content; F.P.: study conception and design, data collection, interpretation and analysis, drafting of the manuscript, critical revision for important intellectual content. All authors have read and agreed to the published version of the manuscript.

Funding: This research received no external funding.

Institutional Review Board Statement: The study was approved by the research ethics committee of Lille University Hospital.

Informed Consent Statement: Informed consent was obtained from all subjects involved in the study.

Data Availability Statement: The data presented in this study are available on reasonable request from the corresponding author, subject to approval by the research ethics committee of Lille University Hospital.

Conflicts of Interest: B.L., J.P., A.C., H.F., V.S., A.S., C.V.G., J.H., E.C., D.M., and F.P. have no competing interests. They are employed by an institution engaged in a contractual collaboration with Siemens Healthcare. M.S., C.F., and S.T. are employees of Siemens Healthcare GmbH.

\section{References}

1. Khairy, P.; Ionescu-Ittu, R.; Mackie, A.S.; Abrahamowicz, M.; Pilote, L.; Marelli, A.J. Changing Mortality in Congenital Heart Disease. J. Am. Coll. Cardiol. 2010, 56, 1149-1157. [CrossRef] [PubMed]

2. Baumgartner, H.; De Backer, J.; Babu-Narayan, S.V.; Budts, W.; Chessa, M.; Diller, G.-P.; Lung, B.; Kluin, J.; Lang, I.M.; Meijboom, F.; et al. 2020 ESC Guidelines for the Management of Adult Congenital Heart Disease. Eur. Heart J. 2021, 42, 563-645. [CrossRef]

3. Vincenti, G.; Monney, P.; Chaptinel, J.; Rutz, T.; Coppo, S.; Zenge, M.O.; Schmidt, M.; Nadar, M.S.; Piccini, D.; Chèvre, P.; et al. Compressed Sensing Single-Breath-Hold CMR for Fast Quantification of LV Function, Volumes, and Mass. J. Am. Coll. Cardiol. Imaging 2014, 7, 882-892. [CrossRef] [PubMed]

4. Kido, T.; Kido, T.; Nakamura, M.; Watanabe, K.; Schmidt, M.; Forman, C.; Mochizuki, T. Compressed Sensing Real-Time Cine Cardiovascular Magnetic Resonance: Accurate Assessment of Left Ventricular Function in a Single-Breath-Hold. J. Cardiovasc. Magn. Reson. 2016, 18, 50-60. [CrossRef]

5. Sudarski, S.; Henzler, T.; Haubenreisser, H.; Dösch, C.; Zenge, M.O.; Schmidt, M.; Nadar, M.S.; Borggrefe, M.; Schoenberg, S.O.; Papavassiliu, T. Free-Breathing Sparse Sampling Cine MR Imaging with Iterative Reconstruction for the Assessment of Left Ventricular Function and Mass at 3.0 T. Radiology 2017, 282, 74-83. [CrossRef]

6. Allen, B.D.; Carr, M.; Botelho, M.P.F.; Rahsepar, A.A.; Markl, M.; Zenge, M.O.; Schmidt, M.; Nadar, M.S.; Spottiswoode, B.; Collins, J.D.; et al. Highly Accelerated Cardiac MRI Using Iterative SENSE Reconstruction: Initial Clinical Experience. Int. J. Cardiovasc. Imaging 2016, 32, 955-963. [CrossRef] [PubMed]

7. Camargo, G.C.; Erthal, F.; Sabioni, L.; Penna, F.; Strecker, R.; Schmidt, M.; Zenge, M.O.; Lima, R.d.S.L.; Gottlieb, I. Real-Time Cardiac Magnetic Resonance Cine Imaging with Sparse Sampling and Iterative Reconstruction for Left-Ventricular Measures: Comparison with Gold-Standard Segmented Steady-State Free Precession. Magn. Reson. Imaging 2017, 38, 138-144. [CrossRef] [PubMed]

8. Goebel, J.; Nensa, F.; Bomas, B.; Schemuth, H.P.; Maderwald, S.; Gratz, M.; Quick, H.H.; Schlosser, T.; Nassenstein, K. Real-Time SPARSE-SENSE Cardiac Cine MR Imaging: Optimization of Image Reconstruction and Sequence Validation. Eur. Radiol. 2016, 26, 4482-4489. [CrossRef] [PubMed]

9. Kido, T.; Kido, T.; Nakamura, M.; Watanabe, K.; Schmidt, M.; Forman, C.; Mochizuki, T. Assessment of Left Ventricular Function and Mass on Free-Breathing Compressed Sensing Real-Time Cine Imaging. Circ. J. 2017, 81, 1463-1468. [CrossRef]

10. Bogachkov, A.; Ayache, J.B.; Allen, B.D.; Murphy, I.; Carr, M.L.; Spottiswoode, B.; Schmidt, M.; Zenge, M.O.; Nadar, M.S.; Zuehlsdorff, S.; et al. Right Ventricular Assessment at Cardiac MRI: Initial Clinical Experience Utilizing an IS-SENSE Reconstruction. Int. J. Cardiovasc. Imaging 2016, 32, 1081-1091. [CrossRef] [PubMed]

11. Haubenreisser, H.; Henzler, T.; Budjan, J.; Sudarski, S.; Zenge, M.O.; Schmidt, M.; Nadar, M.S.; Borggrefe, M.; Schoenberg, S.O.; Papavassiliu, T. Right Ventricular Imaging in 25 Seconds: Evaluating the Use of Sparse Sampling CINE with Iterative Reconstruction for Volumetric Analysis of the Right Ventricle. Investig. Radiol. 2016, 51, 379-386. [CrossRef]

12. Klinke, V.; Muzzarelli, S.; Lauriers, N.; Locca, D.; Vincenti, G.; Monney, P.; Lu, C.; Nothnagel, D.; Pilz, G.; Lombardi, M.; et al. Quality Assessment of Cardiovascular Magnetic Resonance in the Setting of the European CMR Registry: Description and Validation of Standardized Criteria. J. Cardiovasc. Magn. Reson. 2013, 15, 55. [CrossRef]

13. Benchoufi, M.; Matzner-Lober, E.; Molinari, N.; Jannot, A.-S.; Soyer, P. Interobserver Agreement Issues in Radiology. Diagn. Interv. Imaging 2020, 101, 639-641. [CrossRef] [PubMed] 
14. Myerson, S.G. Valvular and Hemodynamic Assessment with CMR. Heart Fail. Clin. 2009, 5, 389-400. [CrossRef] [PubMed]

15. Plein, S.; Bloomer, T.N.; Ridgway, J.P.; Jones, T.R.; Bainbridge, G.J.; Sivananthan, M.U. Steady-State Free Precession Magnetic Resonance Imaging of the Heart: Comparison with Segmented k-Space Gradient-Echo Imaging. J. Magn. Reson. Imaging 2001, 14, 230-236. [CrossRef] [PubMed]

16. Pennell, D.J.; Sechtem, U.P.; Higgins, C.B.; Manning, W.J.; Pohost, G.M.; Rademakers, F.E.; van Rossum, A.C.; Shaw, L.J.; Yucel, E.K.; Society for Cardiovascular Magnetic Resonance; et al. Clinical Indications for Cardiovascular Magnetic Resonance (CMR): Consensus Panel Report. Eur. Heart J. 2004, 25, 1940-1965. [CrossRef]

17. Kramer, C.M.; Barkhausen, J.; Bucciarelli-Ducci, C.; Flamm, S.D.; Kim, R.J.; Nagel, E. Standardized Cardiovascular Magnetic Resonance Imaging (CMR) Protocols: 2020 Update. J. Cardiovasc. Magn. Reson. 2020, 22, 17. [CrossRef]

18. Vermersch, M.; Longère, B.; Coisne, A.; Schmidt, M.; Forman, C.; Monnet, A.; Pagniez, J.; Silvestri, V.; Simeone, A.; Cheasty, E.; et al. Compressed Sensing Real-Time Cine Imaging for Assessment of Ventricular Function, Volumes and Mass in Clinical Practice. Eur. Radiol. 2020, 30, 609-619. [CrossRef]

19. Steeden, J.A.; Kowalik, G.T.; Tann, O.; Hughes, M.; Mortensen, K.H.; Muthurangu, V. Real-Time Assessment of Right and Left Ventricular Volumes and Function in Children Using High Spatiotemporal Resolution Spiral BSSFP with Compressed Sensing. J. Cardiovasc. Magn. Reson. 2018, 20, 79. [CrossRef]

20. Clarke, C.J.; Gurka, M.J.; Norton, P.T.; Kramer, C.M.; Hoyer, A.W. Assessment of the Accuracy and Reproducibility of RV Volume Measurements by CMR in Congenital Heart Disease. J. Am. Coll. Cardiol. Imaging 2012, 5, 28-37. [CrossRef]

21. Schulz-Menger, J.; Bluemke, D.A.; Bremerich, J.; Flamm, S.D.; Fogel, M.A.; Friedrich, M.G.; Kim, R.J.; von KnobelsdorffBrenkenhoff, F.; Kramer, C.M.; Pennell, D.J.; et al. Standardized Image Interpretation and Post-Processing in Cardiovascular Magnetic Resonance-2020 Update. J. Cardiovasc. Magn. Reson. 2020, 22, 19. [CrossRef]

22. Winter, M.M.; Bernink, F.J.; Groenink, M.; Bouma, B.J.; van Dijk, A.P.; Helbing, W.A.; Tijssen, J.G.; Mulder, B.J. Evaluating the Systemic Right Ventricle by CMR: The Importance of Consistent and Reproducible Delineation of the Cavity. J. Cardiovasc. Magn. Reson. 2008, 10, 40. [CrossRef] [PubMed]

23. Fratz, S.; Chung, T.; Greil, G.F.; Samyn, M.M.; Taylor, A.M.; Valsangiacomo Buechel, E.R.; Yoo, S.-J.; Powell, A.J. Guidelines and Protocols for Cardiovascular Magnetic Resonance in Children and Adults with Congenital Heart Disease: SCMR Expert Consensus Group on Congenital Heart Disease. J. Cardiovasc. Magn. Reson. 2013, 15, 51. [CrossRef] [PubMed]

24. Bonello, B.; Kilner, P.J. Review of the Role of Cardiovascular Magnetic Resonance in Congenital Heart Disease, with a Focus on Right Ventricle Assessment. Arch. Cardiovasc. Dis. 2012, 105, 605-613. [CrossRef] [PubMed]

25. Wang, J.; Li, X.; Lin, L.; Dai, J.-W.; Schmidt, M.; Forman, C.; An, J.; Jin, Z.-Y.; Wang, Y.-N. Diagnostic Efficacy of 2-Shot Compressed Sensing Cine Sequence Cardiovascular Magnetic Resonance Imaging for Left Ventricular Function. Cardiovasc. Diagn. Ther. 2020, 10, 431-441. [CrossRef] [PubMed]

26. Kellman, P.; Chefd'hotel, C.; Lorenz, C.H.; Mancini, C.; Arai, A.E.; McVeigh, E.R. High Spatial and Temporal Resolution Cardiac Cine MRI from Retrospective Reconstruction of Data Acquired in Real Time Using Motion Correction and Resorting. Magn. Reson. Med. 2009, 62, 1557-1564. [CrossRef]

27. Rizk, J. 4D Flow MRI Applications in Congenital Heart Disease. Eur. Radiol. 2021, 31, 1160-1174. [CrossRef] [PubMed]

28. Gabiano, E.; Silvestri, V.; Pagniez, J.; Simeone, A.; Hennicaux, J.; Longere, B.; Pontana, F. Le flux 4D: Technique et principales applications pour l'étude de l'aorte thoracique. J. Imaging Diagn. Interv. 2020. [CrossRef]

29. Barker, N.; Fidock, B.; Johns, C.S.; Kaur, H.; Archer, G.; Rajaram, S.; Hill, C.; Thomas, S.; Karunasaagarar, K.; Capener, D.; et al. A Systematic Review of Right Ventricular Diastolic Assessment by 4D Flow CMR. BioMed Res. Int. 2019, 2019. [CrossRef]

30. Tariq, U.; Hsiao, A.; Alley, M.; Zhang, T.; Lustig, M.; Vasanawala, S.S. Venous and Arterial Flow Quantification Are Equally Accurate and Precise with Parallel Imaging Compressed Sensing 4D Phase Contrast MRI. J. Magn. Reson. Imaging 2013, 37, 1419-1426. [CrossRef]

31. Longere, B.; Braye, G.; Pagniez, J.; Silvestri, V.; Simeone, A.; Kasprzak, K.; Monnet, A.; Pontana, F. Compressed Sensing 4D Flow MRI for the Assessment of the Left Ventricular Stroke Volume. In Proceedings of the European Society of Cardiovascular Radiology Congress, Antwerp, Belgium, 24-26 October 2019; p. P-0047.

32. Hsiao, A.; Lustig, M.; Alley, M.T.; Murphy, M.; Chan, F.P.; Herfkens, R.J.; Vasanawala, S.S. Rapid Pediatric Cardiac Assessment of Flow and Ventricular Volume with Compressed Sensing Parallel Imaging Volumetric Cine Phase-Contrast MRI. Am. J. Roentgenol. 2012, 198, W250-W259. [CrossRef] [PubMed]

33. Longère, B.; Chavent, M.-H.; Coisne, A.; Gkizas, C.; Pagniez, J.; Simeone, A.; Silvestri, V.; Schmidt, M.; Forman, C.; Montaigne, D.; et al. Single Breath-Hold Compressed Sensing Real-Time Cine Imaging to Assess Left Ventricular Motion in Myocardial Infarction. Diagn. Interv. Imaging 2020. [CrossRef]

34. Goebel, J.; Nensa, F.; Schemuth, H.P.; Maderwald, S.; Gratz, M.; Quick, H.H.; Schlosser, T.; Nassenstein, K. Compressed Sensing Cine Imaging with High Spatial or High Temporal Resolution for Analysis of Left Ventricular Function. J. Magn. Reson. Imaging 2016, 44, 366-374. [CrossRef] [PubMed]

35. Lin, A.C.W.; Strugnell, W.; Riley, R.; Schmitt, B.; Zenge, M.; Schmidt, M.; Morris, N.R.; Hamilton-Craig, C. Higher Resolution Cine Imaging with Compressed Sensing for Accelerated Clinical Left Ventricular Evaluation. J. Magn. Reson. Imaging 2017, 45, 1693-1699. [CrossRef] [PubMed] 
36. Wetzl, J.; Schmidt, M.; Pontana, F.; Longère, B.; Lugauer, F.; Maier, A.; Hornegger, J.; Forman, C. Single-Breath-Hold 3-D CINE Imaging of the Left Ventricle Using Cartesian Sampling. MAGMA 2017, 31, 19-31. [CrossRef] [PubMed]

37. Blalock, S.E.; Banka, P.; Geva, T.; Powell, A.J.; Zhou, J.; Prakash, A. Interstudy Variability in Cardiac Magnetic Resonance Imaging Measurements of Ventricular Volume, Mass, and Ejection Fraction in Repaired Tetralogy of Fallot: A Prospective Observational Study. J. Magn. Reson. Imaging 2013, 38, 829-835. [CrossRef]

38. Leiner, T.; Bogaert, J.; Friedrich, M.G.; Mohiaddin, R.; Muthurangu, V.; Myerson, S.; Powell, A.J.; Raman, S.V.; Pennell, D.J. SCMR Position Paper (2020) on Clinical Indications for Cardiovascular Magnetic Resonance. J. Cardiovasc. Magn. Reson. 2020, 22, 76. [CrossRef] [PubMed] 